\title{
Regional warming changes fish species richness in the eastern North Atlantic Ocean
}

\author{
Remment ter Hofstede $^{1, *}$, Jan Geert Hiddink ${ }^{2}$, Adriaan D. Rijnsdorp ${ }^{1}$ \\ ${ }^{1}$ IMARES, Institute for Marine Resources \& Ecosystem Studies, IJmuiden 1976 CP, The Netherlands \\ ${ }^{2}$ School of Ocean Sciences, Bangor University, Anglesey LL59 5AB, UK
}

\begin{abstract}
Regional warming causes changes in local communities due to species extinctions and latitudinal range shifts. We show that the species richness of fish in 3 regional seas in the eastern North Atlantic Ocean has changed over time (1997 to 2008), and we relate this to higher water temperatures and the biogeographic affinity of the species. In the North and Celtic Seas, species richness increased due to increases in the number of warm-favouring Lusitanian species. In the area west of Scotland, species richness decreased because the number of cold-favouring Boreal species decreased. Additional analyses of trends in fishing effort imply that the observed changes in species richness are unlikely to have been induced by fisheries in the North and Celtic Seas, thereby strengthening the idea that climate change affects species richness of marine fish. However, in the area west of Scotland, a potential effect of fisheries in addition to temperature change on the observed change in species richness could not be ruled out.
\end{abstract}

KEY WORDS: Climate change ' Species richness Biogeography · International Bottom Trawl Surveys · IBTS · North Sea $\cdot$ Celtic Sea $\cdot$ West of Scotland

Resale or republication not permitted without written consent of the publisher

\section{INTRODUCTION}

The Earth's climate has warmed by approximately $0.6^{\circ} \mathrm{C}$ over the past century (Walther et al. 2002), and temperature is expected to continue rising. Global warming has altered natural systems (e.g. Petchey et al. 1999, Root et al. 2003), and climate change has been predicted to lead to species extinctions (Thomas et al. 2004) and to poleward shifting of the latitudinal distribution ranges of species (Parmesan \& Yohe 2003).

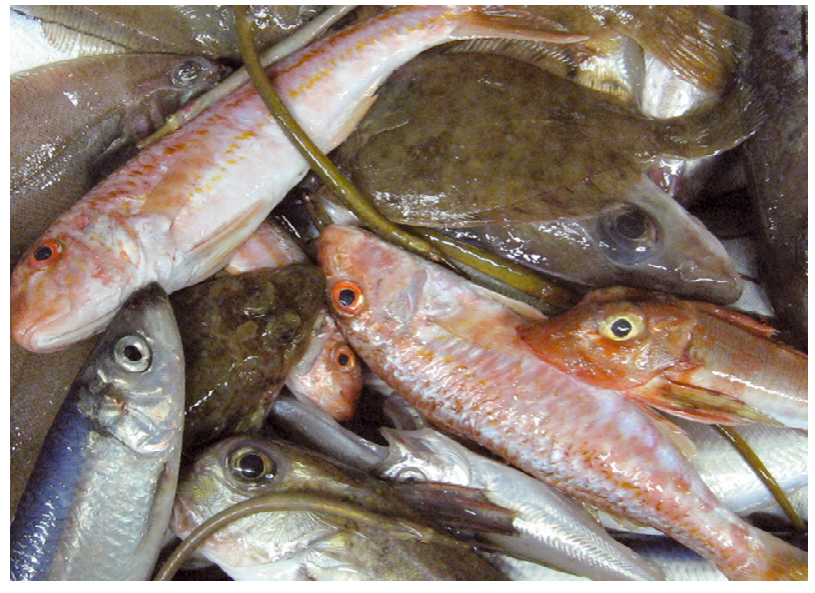

Abundance of warm water species such as the snake pipefish, red mullet and gurnards has been increasing in the Northeast Atlantic in response to climate change.

Photo: R. ter Hofstede

When species' ranges shift due to large-scale climatic forcing, the diversity of local communities will change in response (Fisher et al. 2008). Communities at temperate latitudes will gain species from equatorial directions, for which the higher temperatures that were previously too cold become suitable, and lose species to poleward regions, for which conditions become too warm. Whether organisms will be able to shift their occupied areas polewards with increasing temperatures depends on the dispersal potential of the species, the connectivity of suitable habitat patches and the rate of temperature change.

Previous studies have indicated that important increases in species richness as a result of global warming can be expected in a wide range of ecosystems and organisms. Large-scale increases in species richness 
have been recorded for butterflies (Menéndez et al. 2006), freshwater fish (Daufresne \& Boet 2007, Daufresne et al. 2004) and marine fish (Henderson 2007, Hiddink \& ter Hofstede 2008). In each of these studies, the number of warm-favouring species increased, while only few cold-favouring species were lost. A consensus has emerged that many species are expanding their distributions towards the poles and to higher elevations in response to climate change, but corresponding evidence for range retractions at low latitude and low elevation boundaries has been comparatively weak. It is unclear why not more species are observed retreating in these regions (Thomas et al. 2006).

Coastal marine ecosystems are among the most socio-economically and ecologically important habitats, and these ecosystems are warming at a much faster rate than many other ecosystems (MacKenzie \& Schiedek 2007). Within the marine environment, climate change is suggested to affect the distribution, abundance and assemblage composition of fish. Future climate change is predicted to lead to dramatic species turnovers of the present biodiversity, implying serious ecological disturbances of the marine environment (Cheung et al. 2009). Such processes will influence the nature and value of commercial fisheries in these ecosystems.

A regional change in water temperature may lead to changes in the local fish community because of immigration and/or emigration of species with different temperature preferences (Blanchard et al. 2005). Macpherson (2002) showed a clear latitudinal gradient in marine species richness to increase from the poles to the Equator, and subsequently it is expected that higher water temperatures will result in increasing marine fish species richness. In general, a warming environment would result in poleward advances of species with an affinity to warm water (Lusitanian) and retreats of species with an affinity to cooler water (Boreal) (Brander et al. 2003, Southward et al. 2005, Stefansdottir et al. 2010).

The ecological effects of climate change are likely to be region-specific and may vary widely depending on species and community characteristics and specific regional conditions (Walther et al. 2002). To date, most studies of the ecological effect of climate change on marine fish have largely concentrated on the impact at the individual species level (e.g. Attrill \& Power 2002, Perry et al. 2005, Dulvy et al. 2008, Nye et al. 2009) rather than on community metrics such as species richness (i.e. the number of species observed). In this study, we compared trends in fish species richness among 3 regions in the eastern Atlantic Ocean, namely (1) the North Sea, (2) the Celtic Sea, and (3) off the west coast of Scotland. Differences in the local physical environment such as variation in summer and winter temperatures, and depth ranges, clearly cause differ- ences in species richness among the 3 regions. We therefore examined area-specific changes in species richness. Trends in species richness for marine fish in the North Sea have been related to temperature in a previous study (Hiddink \& ter Hofstede 2008); these data were reanalysed using a shorter time series to standardise the analyses between the different areas used. Our objective was to determine whether species richness of marine fish in the 3 different regions displays similar trends through time and whether it has a consistent relation to bottom temperature. If warming is the cause of changes in fish species composition, it can be expected that the change in species richness relates to the biogeographic affinity of species, such that Boreal (cold-favouring) species decrease in abundance, while Lusitanian (warm-favouring) species increase in abundance. A consistent relationship between temperature change and changes in species richness will indicate that large-scale increases in species can be expected in temperate marine ecosystems.

\section{MATERIALS AND METHODS}

Survey data. Annual data describing the fish distribution (including elasmobranchs) in the 3 different study areas during the winter were taken from 3 International Bottom Trawl Surveys (IBTS) coordinated by the International Council for the Exploration of the Sea (ICES), namely the first quarter IBTS in the North Sea, the first quarter Western Division Bottom Trawl Survey in the Inland Sea off the west coast of Scotland, and the fourth quarter French Groundfish Survey in the Celtic Sea. These surveys aimed for coherence and consistency in the collected data by standardising their sampling methods and protocols (ICES 2008a). All surveys used a standard bottom-trawl net (chalut à grande ouverture verticale, GOV-trawl), a gear that is specifically designed to sample fish that live at and above the seabed (Heessen et al. 1997).

When comparing surveys, differences in sampling method (gear) contribute more to the variance in abundance estimates compared to survey period (quarter) (Trenkel et al. 2004). Since the 3 studied areas were sampled according to a corresponding standard IBTS protocol, and both studied quarters (1 and 4) comprised a cold season, we considered it appropriate to compare the surveys from these 3 regions.

The IBTS in the North Sea and west of Scotland followed a sampling strategy according to a grid of ICES rectangles $\left(0.5^{\circ}\right.$ latitude; $1^{\circ}$ longitude; approximately $56 \times 56 \mathrm{~km}$ ). The IBTS in the Celtic Sea is in principle depth-stratified, but to allow a uniform analysis, the aggregation was performed following the grid of ICES rectangles. Details of the gear and sampling strategies 
can be found in the manuals for the 3 surveys (ICES 2002, 2006). The data were extracted from the ICES Database for Trawl Surveys (DATRAS, downloaded 17 July 2009; http://datras.ices.dk).

Fish data. Catch rates were standardised to the number of individuals caught per 60 min tow. The time period during which all surveys had an overlap in sound coverage of the different areas comprised more than a decade (1997 to 2008). Such a time series is of sufficient power to detect trends in both common and rare fish species (Maxwell \& Jennings 2005).

To avoid the introduction of temporal trends that may be related to differences in the sampled survey area over time, only rectangles fished in at least $75 \%$ of the years were used (Fig. 1). In total, 210 of the 262 fished ICES rectangles were used in the analysis. The number of hauls per rectangle was distributed unevenly within each area, ranging between 1 and 6 hauls $\mathrm{yr}^{-1}$, on average $2.1 \pm 0.8$ hauls per rectangle in the North Sea, $2.0 \pm 1.0$ in the Celtic Sea, and $1.3 \pm 0.6$ in the west of Scotland. Since the number of species caught is positively correlated to the number of hauls fished (Daan 2006), the dataset was balanced before using it for further analyses by applying the Monte Carlo resampling strategy. For each ICES rectangle and year, 1 haul was randomly selected, and this process was repeated 100 times. These 100 random selec-

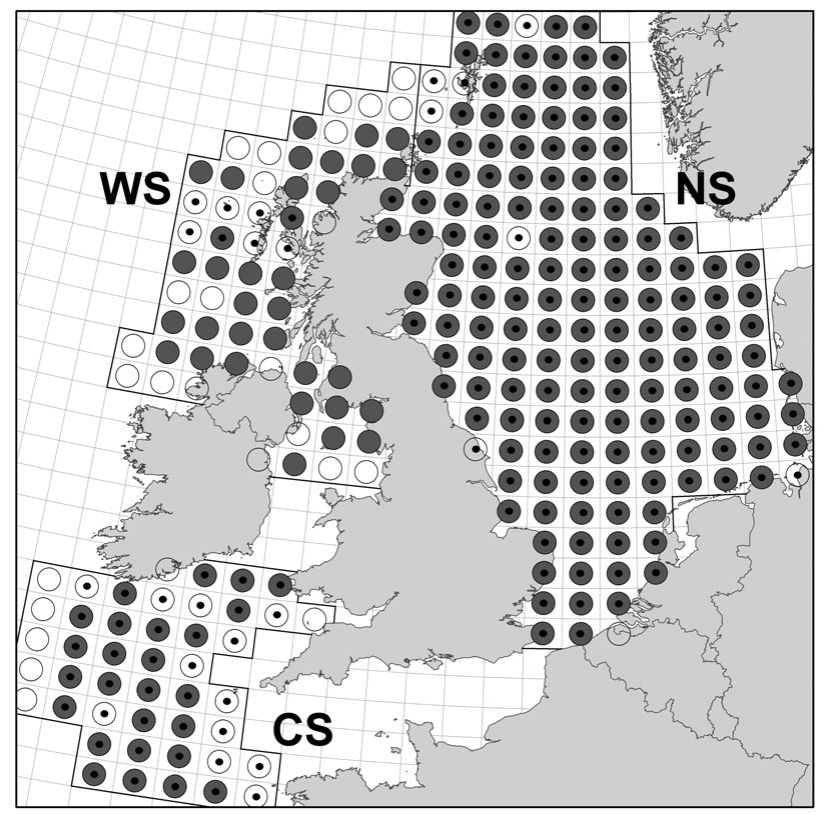

Fig. 1. Location of the 3 studied areas (NS: North Sea; CS: Celtic Sea; WS: west of Scotland). Open circles represent surveyed International Council for the Exploration of the Sea (ICES) rectangles; grey circles show the ICES rectangles used in the analyses (>75\% annual coverage). Black dots indicate ICES rectangles that were used for the calculation of average bottom temperatures tions were averaged, resulting in 1 balanced dataset on which further analyses were performed.

Fish were identified to the lowest possible taxonomic level, which was mostly to species level; however, for consistency, we refer to all taxa as species. All species were labelled with their biogeographic affinity, i.e. Atlantic (widespread), Boreal (northern, coldfavouring) or Lusitanian (southern, warm-favouring), which was derived from the literature following the approach of Yang (1982), with inclusion of fish species that have been recorded since then (Wheeler 1992, Froese \& Pauly 2009, Wheeler et al. 2004, Ellis et al. 2010). In Europe, Boreal fishes are those considered to be northerly taxa which extend northwards to the Norwegian Sea and Icelandic waters. These fishes often have their southern limits of distribution around the British Isles or west of Brittany, although some may still occur further south, either in low numbers or as vagrants. Lusitanian fishes are those that tend to be abundant from the Iberian Peninsula (including the Mediterranean Sea) to as far north as the British Isles, and may have northerly limits in the southern or central North Sea (although many such species do extend to more northerly latitudes on the western seaboards of the British Isles, and so can also occur in the northwestern North Sea). Many of these species have distributions extending into the Mediterranean Sea and off the coast of northwest Africa. Atlantic species are those (often pelagic or deep-water) species that are widespread in the North Atlantic, and include many of the deeper-water or mesopelagic species that may be widely distributed along the continental slope.

Corrections for misidentifications were made following the approach of ter Hofstede \& Daan (2008). In addition, some fish in the families Myctophidae, Serranidae, Percichthyidae, Blenniidae, Stichtaeidae, Callionymidae, Gobiidae, Bothidae and Rajidae were only identified to the family level. To avoid misinterpretation for non-existing species, these records were not included in the analysis. The final list of taxa that could be characterised contained 117 fish species for the North Sea (8 Atlantic, 48 Boreal, 61 Lusitanian), 115 species for the Celtic Sea (17 Atlantic, 25 Boreal, 73 Lusitanian), and 100 species for the area west of Scotland (9 Atlantic, 34 Boreal, 57 Lusitanian).

Temperature data. Bottom temperature data were obtained from the ICES Oceanographic Database (downloaded 29 June 2009; www.ices.dk/ocean), for the areas and quarters corresponding to those in which the 3 surveys were executed. The time series of these winter temperature data was available in higher quantities, in particular spatially, than for the other seasons; therefore, we chose to work only with data from the winter period. Bottom data were defined as the deepest measurement taken with a vertical CTD cast, in 
general around $5 \mathrm{~m}$ above the bottom. The data were averaged per quarter by ICES rectangle. To ensure a balanced dataset, missing data were interpolated from adjacent data by averaging the mean bottom temperature of the 8 surrounding rectangles. This interpolation was performed for less than $14 \%$ of the year-rectangle combinations. The bottom temperature data series covers the time period 1993 to 2008 to allow for the calculation of 5 yr running means. For the Celtic Sea, data were missing during the years 1995, 2007 and 2008, and in the area west of Scotland during the years 1997 to 1999. Furthermore, in the surveyed area west of Scotland, the available temperature data did not spatially cover the area sufficiently for use in the analysis; therefore, 8 ICES rectangles (42E0 to 42E3 and 43E0 to $43 \mathrm{E} 3$ ) that lie in the centre of the area and for which data are sufficiently available were selected to represent the entire area.

Temporal trends in species richness for all fish species, Boreal species, and Lusitanian species were analysed using linear regression. Species richness was related to the 5 yr running average bottom temperature, calculated from the current year and the 4 previous years, to allow for potential lagged effects. Using a time lag is a fairly common method to approximate the lifetime environmental experience of a fish (e.g. Perry et al. 2005, Dulvy et al. 2008), and species richness responded most significantly to $5 \mathrm{yr}$ running means of winter bottom temperature. In case of years with missing temperature data, the $5 \mathrm{yr}$ running means were based on the available years only. The relation between richness and temperature was tested using Pearson's correlation coefficient (r), on a year basis.

Fishing effort data. To discuss whether observed changes in species richness may have been induced by fisheries, we checked for changes in fishing effort in the 3 different areas. We assumed that changes in fishing effort are reflected in the average fishing mortalities of the dominant commercial fish stocks estimated by ICES assessment working groups (ICES 2008b, 2009). Only the demersal fisheries that are of main importance in terms of effort were considered, which are plaice, sole, cod, Norway pout, haddock and saithe in the North Sea (ICES 2009); plaice, sole and cod in the Celtic Sea (ICES 2008b), and haddock, saithe and cod in the area west of Scotland (ICES 2008b). The response of fish to changes in exploitation is expected to show a time lag; for example, Daan et al. (2005) noted a response time of $6 \mathrm{yr}$ for an increase in species richness in relation to an increase in fishing effort. In our case, when ignoring a time lag, we observed no correlation between fisheries effects and species richness. To allow for potential lagged effects, species richness was therefore related to the 6 yr running average fishing mortality, calculated from the current year and the 5 previous years for the period 1992 to 2008. The relation between species richness and fishing mortality was tested using Pearson's correlation coefficient (r), on a year basis.

Autocorrelation. Autocorrelation in fish and environmental data may complicate statistical inference in correlation analyses (Pyper \& Peterman 1998). We used the Durbin-Watson statistic $(D)$ on all of our time series to detect the presence of autocorrelation in the residuals from the regression analysis. In general, we found no reason for concern that our data were autocorrelated, thereby justifying our analyses for correlation between species richness versus temperature and fishing effort (bottom temperature: North Sea, NS, $D=$ 1.94; Celtic Sea, CS, $D=1.07$; west of Scotland, WS, $D=1.98$; fishing effort: NS, $D=1.70$; CS, $D=0.56$; WS, $D=1.47$; total species richness: NS, $D=2.67$; $C$, $D=$ 2.48 ; WS, $D=2.43$; Boreal species richness: NS, $D=$ 2.68; CS, $D=2.13$; WS, $D=2.06$; Lusitanian species richness: NS, $D=1.51$; $\mathrm{CS}, D=2.20$; WS, $D=2.06$ ).

\section{RESULTS}

\section{Temperature}

Winter bottom temperatures have increased significantly since 1993 in all 3 studied regions in the eastern Atlantic Ocean, in the North Sea by $0.09^{\circ} \mathrm{C} \mathrm{yr}^{-1}\left(F_{1,15}=\right.$ $12.01, \mathrm{p}=0.003)$, in the Celtic Sea by $0.04^{\circ} \mathrm{C} \mathrm{yr}^{-1}\left(F_{1,12}=\right.$ $6.46, \mathrm{p}=0.025)$, and in the central part of the area west of Scotland by $0.09^{\circ} \mathrm{C} \mathrm{yr}^{-1}\left(F_{1,12}=0.005, \mathrm{p}=12.03\right.$; Fig. 2a). Surface temperatures from the same areas, obtained from the ICES Oceanographic Database and analysed similarly to the CTD bottom temperature data, showed similar trends, although the rates of change differed slightly (NS: $0.10^{\circ} \mathrm{C} \mathrm{yr}^{-1}, F_{1,15}=13.71$, $\mathrm{p}=0.002 ; \mathrm{CS}: 0.09^{\circ} \mathrm{C} \mathrm{yr}^{-1}, F_{1,12}=4.65, \mathrm{p}=0.052 ; \mathrm{WS}$ : $0.06^{\circ} \mathrm{C} \mathrm{yr}^{-1}, F_{1,12}=7.76, \mathrm{p}=0.017$ ). Surface temperatures were highly correlated to bottom temperatures (NS: $\mathrm{r}=0.96, \mathrm{p}<0.001$; CS: $\mathrm{r}=0.57, \mathrm{p}<0.001$; WS: $\mathrm{r}=$ $0.77, p<0.001$ ), thereby emphasising the strength of the bottom temperature data as used in our analyses.

\section{Species richness}

The annual species richness of the fish fauna in the North Sea (Fig. 3a) and Celtic Sea (Fig. 3b) increased significantly during the studied period (NS: $F_{1,10}=$ 10.91, $\left.\mathrm{p}=0.008) ; \mathrm{CS}: F_{1,9}=15.56, \mathrm{p}=0.003\right)$, whereas a significant decrease was apparent west of Scotland $\left(F_{1,10}=8.28, p=0.016\right.$; Fig. 3c). Taking into account the biogeographic affinity of the fish fauna, the richness of Boreal fish species decreased in the area west of Scot- 

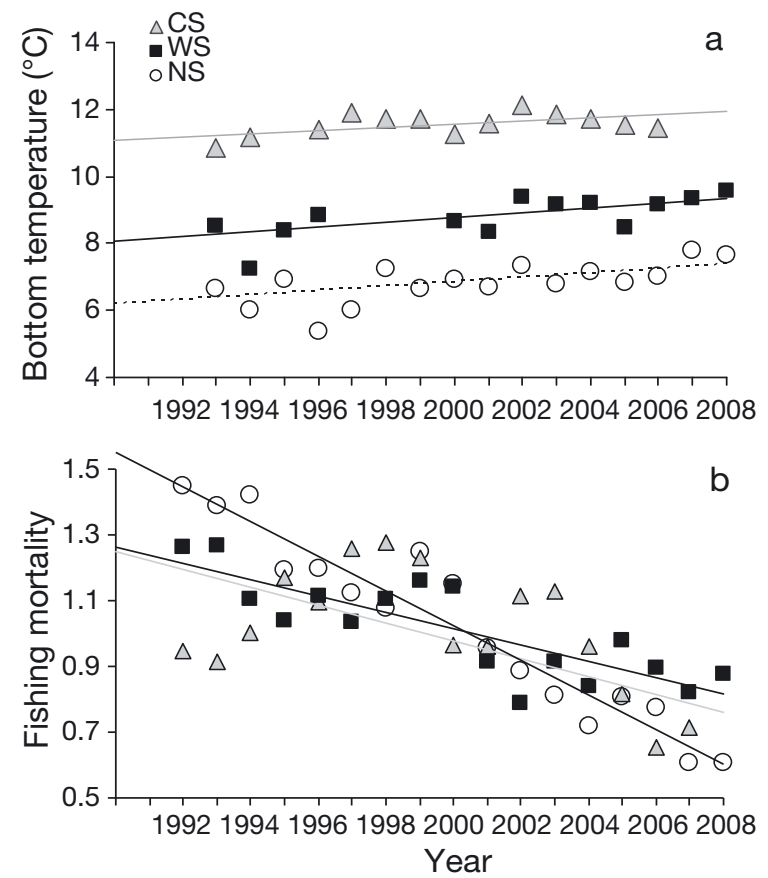

Fig. 2. (a) Average winter bottom temperature and (b) average fishing mortality for major demersal species based on the main demersal fisheries in terms of effort in the North Sea (NS), Celtic Sea (CS), and west of Scotland (WS) for the period 1992 to 2008. Lines indicate significant trends (NS: dashed; CS: grey; WS: black)

land $\left(F_{1,10}=13.53, \mathrm{p}=0.004\right)$, while no trend was observed in the North Sea $\left(F_{1,10}=0.06, \mathrm{p}=0.818\right)$ and Celtic Sea $\left(F_{1,9}=3.51, \mathrm{p}=0.093\right.$; Fig. 3a-c). The richness of Lusitanian species significantly increased in the North Sea $\left(F_{1,10}=19.68, \mathrm{p}=0.001\right)$ and Celtic Sea $\left(F_{1,9}=17.50, \mathrm{p}=0.002\right)$, and did not show a significant change west of Scotland $\left(F_{1,10}=0.08, \mathrm{p}=0.780\right)$.

\section{Species richness versus temperature}

Species richness was significantly positively correlated to the 5 yr running means in bottom temperature in the North Sea $(r=0.69, p=0.012$; Fig. 3d) and Celtic Sea $(r=0.78, p=0.007$; Fig. $3 e)$, while a negative relationship between species richness and temperature was found west of Scotland ( $r=-0.55, \mathrm{p}=0.059$; Fig. 3f). The richness of Boreal species was negatively correlated with temperature west of Scotland $(r=-13.53$, $\mathrm{p}=0.004$ ), while no relation was observed in the North Sea $(r=0.06, p=0.818)$ and in the Celtic Sea $(r=3.51$, $\mathrm{p}=0.093$; Fig. 3d-f). The richness of Lusitanian fish species was significantly positively related to bottom temperature in the North Sea $(r=0.82, p=0.001)$ and Celtic Sea $(r=0.75, p=0.011)$, and did not have a relation with bottom temperature west of Scotland $(\mathrm{r}=$ 0.03, $p=0.906$; Fig. 3d-f).

\section{Fishing effort}

Changes in average fishing mortalities by area over the period 1992 to 2008 were calculated using the main demersal fisheries. The average fishing mortality of these fisheries showed a significant decline in each area over the period 1992 to 2008 (CS: $F_{1,15}=7.38, \mathrm{p}=$ 0.016; NS: $F_{1,15}=185.25, \mathrm{p}<0.001$; WS: $F_{1,15}=33.51$, $\mathrm{p}<0.001$; Fig. 2b).

\section{Species richness versus fishing effort}

Species richness was significantly negatively correlated to the 6 yr running means in average fishing mortality in the North Sea over the period 1997 to 2008 ( $\mathrm{r}=$ $-0.77, \mathrm{p}=0.003$; Fig. 3g); no relationship was found in the Celtic Sea ( $r=-0.49, p=0.127$; Fig. $3 h$ ), and a significant positive relationship was found in the area west of Scotland ( $r=0.64, p=0.025$ ) (Fig. 3i). Taking into consideration the biogeographical guild, for Boreal species a significant positive relationship between species richness and fishing mortality was found in the area west of Scotland ( $r=0.77, p=0.003$ ), while no relationship was observed in the other areas (NS: $\mathrm{r}=$ $-0.13, p=0.695$; CS: $r=-0.28, p=0.408$; Fig. $3 g-i)$. For Lusitanian species, species richness was negatively correlated to fishing mortality in the North Sea ( $\mathrm{r}=$ $-0.91, \mathrm{p}<0.001$ ), while no relationship was found in the Celtic Sea and west of Scotland (CS: $r=-0.54, p=$ 0.083; WS: $r=0.06, p=0.850$; Fig. $3 g-i)$.

\section{DISCUSSION}

Winter bottom temperatures significantly increased in the North Sea and west of Scotland during the period 1993 to 2008, and in the Celtic Sea during the period 1993 to 2006, which is in accordance with recent findings of other studies of sea water temperatures in the Northeast Atlantic (e.g. MacKenzie \& Schiedek 2007, Philippart et al. 2007, Hiddink \& ter Hofstede 2008). Sea surface temperatures increased correspondingly in the areas. Although the observed regional increases in temperature are consistent with the expected increase due to global warming, they are substantially higher than the increase expected from global climate change. This discrepancy is likely related to the effect of regional processes, in particular the Atlantic Multidecadal Oscillation, which shifted to a warm phase during our study period (Enfield et al. 2001, 2010). Furthermore, regional climate-change scenarios around the North Sea predict an increase in air temperature of 2 to $3.5^{\circ} \mathrm{C}$ by the $2080 \mathrm{~s}$, and water temperatures will also increase, but not as rapidly as 

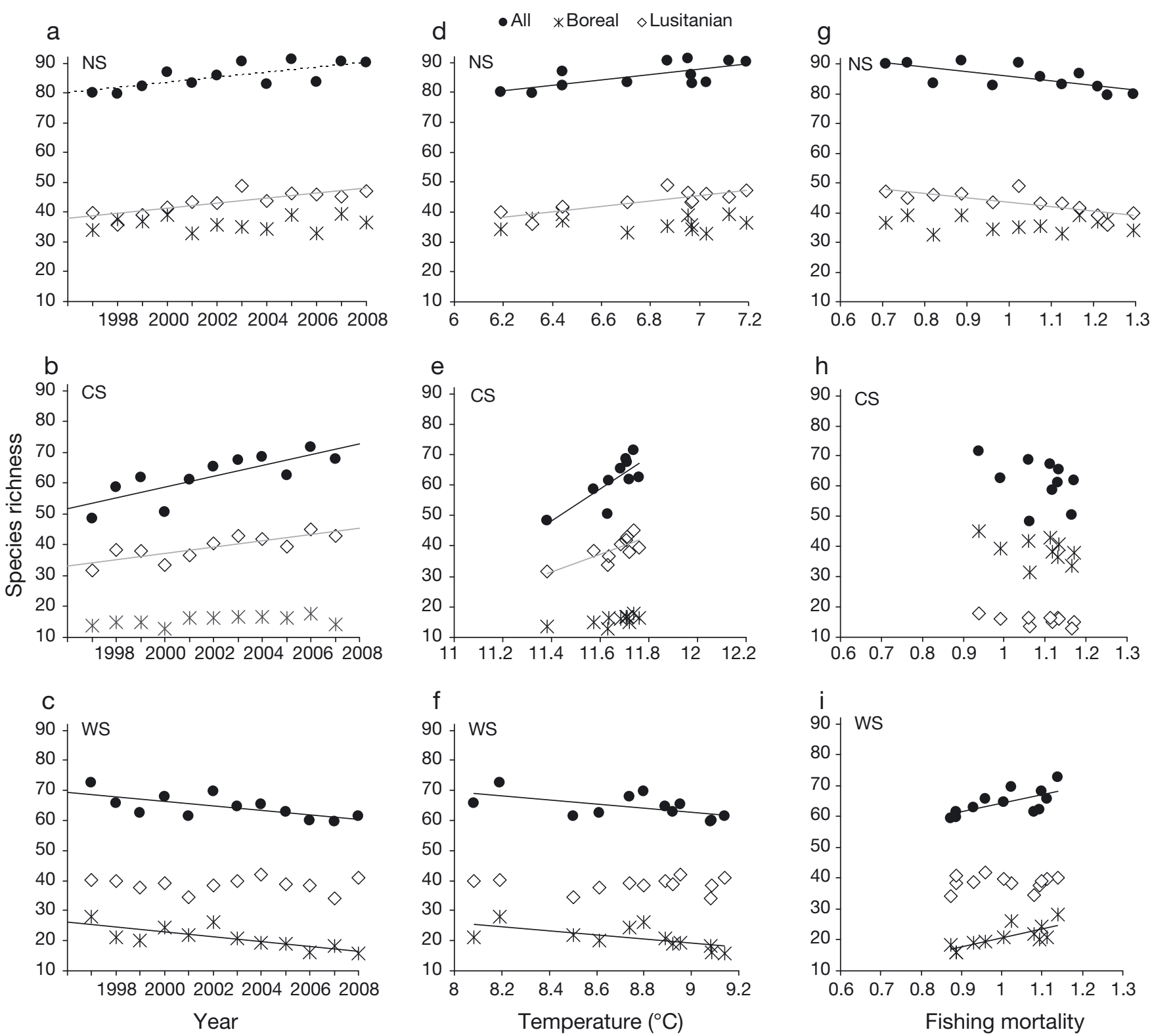

Fig. 3. Change in fish species richness over time (1997 to 2008) and with temperature. Species richness per year for All, Boreal, and Lusitanian fish species in the (a) North Sea (NS), (b) Celtic Sea (CS) and (c) west of Scotland (WS). Species richness for All, Boreal, and Lusitanian species versus the average bottom temperature over the previous 5 yr in (d) NS, (e) CS and (f) WS. Species richness for All, Boreal, and Lusitanian species versus the average fishery mortality for major demersal species over the previous 6 yr in (g) NS, (h) CS and (i) WS. Lines indicate significant correlations (All: black; Boreal: dashed; Lusitanian: grey)

over land (e.g. Hulme et al. 2002). The fast regional warming as observed around the British Isles is likely due to regional processes, not only global ones, and may be attributed to a combination of anthropogenic and natural influences (Stone et al. 2009).

Our analyses showed a significant increase in species richness of marine fish in the North Sea during the years 1997 to 2008, and Celtic Sea over the period 1997 to 2007, areas in which the water temperature had increased significantly during the same period. In both the North and Celtic Seas, the positive change in species richness is significantly related to these higher water temperatures, following the expectations that marine fish species richness correlates positively with temperature (Macpherson 2002, Macpherson \& Duarte 2006). However, in the area west of Scotland, a decrease in species richness was observed, which also significantly correlated to increasing water temperatures. Such findings are unexpected, but may be explained when taking into account the biogeographic affinity of fish species.

In general, a warming environment is expected to result in poleward advances of warm-favouring Lusi- 
tanian species and retreats of cold-favouring Boreal species (Brander et al. 2003, Southward et al. 2005, Rijnsdorp et al. 2009). In the North and Celtic Seas, where bottom temperatures are rising, a significant increase in Lusitanian species richness has been observed, and in both areas the increase in Lusitanian species richness was found to be significantly related to bottom temperature. While Lusitanian species are thought to be positively affected by rising water temperatures, the opposite is expected for Boreal species. In the North and Celtic Seas, no trend in Boreal species richness was observed. However, in the area west of Scotland, although no trend in Lusitanian species richness was observed, the richness of Boreal species showed a significant decrease during the period 1997 to 2008 , and this decrease was found to be significantly correlated to the rise in water temperature. This strong decline in Boreal species richness in the area west of Scotland, in combination with the lack of a trend in Lusitanian species richness, explains the overall decline in species richness in this area in relation to increasing water temperatures.

Temperature change influences the local species diversity by changing species distribution over short time scales, even interannually (Fisher et al. 2008), which may explain in our results the lack of a generic response to warming of the 3 local marine fish communities. Contrasting responses in richness of marine fish to increasing water temperatures have also been found around Iceland over the period 1996 to 2007. Species richness increased with temperature and time southwest of Iceland, but decreased northeast of the country (Stefansdottir et al. 2010). The difference in trends illustrates the importance of performing analyses at the appropriate scale; however, no clear explanations for the observation were given, and it was only expected that both fisheries and the functional characteristics of the ecosystem, such as food-web interactions, are the main causal factors of the different trends in richness within the Icelandic fish community.

The fact that the relationship between climate and marine life is difficult to generalise is also illustrated by a comparison of the planktonic assemblage in relation to hydroclimatic features among 3 different European seas (Beaugrand et al. 2000): A strong negative relationship between the abundance of plankton and air temperature was found in the English Channel; it was weaker in the Celtic Sea and no relationship was found in the Bay of Biscay. The observed differences were attributed to variation in the local physical environment and the biological composition of the regions (Beaugrand et al. 2000).

Changes in the structure of fish communities are often considered to be fisheries-induced (e.g. Pauly et al. 1998, Levin et al. 2006), and fisheries may have played a role in the observed changes in the fish communities in the North Sea, Celtic Sea, and the area west of Scotland. The intensive exploitation of fish communities often leads to substantial reductions in the abundance of target species, in particular the larger predatory species, and changes in species composition (Greenstreet \& Hall 1996, Rice \& Gislason 1996, Daan et al. 2005).

Fishing will alter fish communities by removing species with a high longevity and a large body size (Genner et al. 2010), thereby increasing the opportunities for smaller-sized species to invade the area, amplifying the positive circumstances for the generally small Lusitanian species in times of global warming.

Recent studies have argued that changes in marine fish communities are likely to be caused by the interacting effects of climate change and fisheries, rather than by either of these drivers separately or by simple additive effects (e.g. Perry et al. 2010, Planque et al. 2010). Climate is changing globally, and it is likely that an increase in temperature is contributing to the increase in Lusitanian species or the decrease in Boreal species. However, fishing activities often develop concurrently, making it hard to disentangle their effect from climate change. For example, Daan (2006) argued that although climate change may have had add-on effects, an increase in species richness in the North Sea in the period 1977 to 2005 was an indirect effect of overexploitation. The decrease in larger predatory species was considered to allow smaller prey species to increase in abundance due to a reduction in predation mortality and/or competition. In our study areas, fishing mortality of the main demersal fish species decreased over the period 1992 to 2008 (Fig. 2b). The observed increase in species richness in the Celtic and North Seas coincided with a decrease in fishing effort, contradicting Daan (2006). In fact, we observed no relationship between trends in species richness and fishing mortality in the Celtic Sea, and even a significant negative relationship was shown in the North Sea, both for the overall and Lusitanian species richness. The increase in Lusitanian species richness is less likely to have been caused by a decrease in fisheries, since the opposite would be expected, meaning an increase in fisheries would favour small-sized fish (Genner et al. 2010), and on average Lusitanian species are smaller than Boreal species. In the area west of Scotland, we observed a positive relation between species richness (overall and Boreal) and fishing mortality, meaning that the decrease in overall and Boreal species richness may have been driven by the decline in fishing mortality. Therefore, besides the relationship of species richness with increasing bottom temperatures, fisheries may also have had effects on the richness of marine fish in the area west of Scotland. However, 
notwithstanding the observations in the area west of Scotland, our findings support the idea that the observed changes in species richness in the North and Celtic Seas are likely to be more strongly climate driven than fisheries induced. This would be in line with the observations in other taxa throughout the world, viz. that as temperature rises, species richness increases due a positive correlation between richness and temperature observed along latitudinal gradients. Such increases have been reported for a variety of communities including terrestrial taxa, such as plants (Klanderud \& Birks 2003), birds (La Sorte et al. 2009) and butterflies (Menéndez et al. 2006), for all of which recent climatic change is considered to be the most likely major driving factor. In the marine environment, for example, long-term changes in species composition and diversity of the copepod community have been related to hydroclimatic changes in the Northeast Atlantic, in particular to the variation in decadal oscillations (Beaugrand 2003). During the positive phase of the North Atlantic Oscillation, which occurred in the 1990s, sea temperatures increased, and the plankton community of the temperate waters was replaced by a southern community.

It is generally accepted that major changes have occurred in the fish communities of the Northeast Atlantic during recent decades (e.g. Pauly et al. 1998, Attrill \& Power 2002). Assuming that the sea temperature warming rates will follow the global consensus view of warming (Kerr 2004), the general poleward decline in species richness will decrease (Fisher et al. 2008), and regionally the recent observed increases in fish species richness in the North and Celtic Seas will continue. Such changes in species biogeography, including the change in composition of the fish communities (fewer Boreal and more Lusitanian species), will undoubtedly have implications for commercial fisheries and on the implementation of effective conservation and environmental monitoring strategies.

Acknowledgements. This study was carried out as part of the European Union FP6 project RECLAIM (Contract 044133). We acknowledge the International Council for the Exploration of the Sea (ICES) for supplying data from the ICES hydrographic database and from the database for trawl surveys (DATRAS), and N. Hintzen for assisting in interpolating the temperature datasets. Comments provided by 3 anonymous referees helped to improve the quality of the manuscript.

\section{LITERATURE CITED}

Attrill MJ, Power AJ (2002) Climatic influence on a marine fish assemblage. Nature 417:275-278

> Beaugrand G (2003) Long-term changes in copepod abundance and diversity in the north-east Atlantic in relation to fluctuations in the hydroclimatic environment. Fish Oceanogr 12:270-283
Beaugrand G, Ibañez F, Reid PC (2000) Spatial, seasonal and long-term fluctuations of plankton in relation to hydroclimatic features in the English Channel, Celtic Sea and Bay of Biscay. Mar Ecol Prog Ser 200:93-102

Blanchard JL, Dulvy NK, Jennings S, Ellis JR, Pinnegar JK, Tidd A, Kell LT (2005) Do climate and fishing influence size-based indicators of Celtic Sea fish community structure? ICES J Mar Sci 62:405-411

Brander K, Blom G, Borges MF, Erzini K and others (2003) Changes in fish distribution in the eastern North Atlantic: Are we seeing a coherent response to changing temperature? ICES Mar Sci Symp 219:261-270

Cheung WWL, Lam VWY, Sarmiento JL, Kearny K, Watson R, Pauly D (2009) Projecting global marine biodiversity impacts under climate change senarios. Fish Fish 10: $235-251$

Daan N (2006) Spatial and temporal trends in species richness and abundance for the southerly and northerly components of the North Sea fish community separately, based on IBTS data 1977-2005. ICES CM 2006/D:02. ICES, Copenhagen

> Daan N, Gislason H, Pope JG, Rice JC (2005) Changes in the North Sea fish community: evidence of indirect fishing? ICES J Mar Sci 62:177-188

> Daufresne M, Boet P (2007) Climate change impacts on structure and diversity of fish communities in rivers. Glob Change Biol 13:2467-2478

Daufresne M, Roger MC, Capra H, Lamouroux N (2004) Long-term changes within the invertebrate and fish communities of the Upper Rhône River: effects of climatic factors. Glob Change Biol 10:124-140

> Dulvy NK, Rogers SI, Jennings S, Stelzenmüller V, Dye SR, Sjkoldal HR (2008) Climate change and deepening of the North Sea fish assemblage: a biotic indicator of warming seas. J Appl Ecol 45:1029-1039

Ellis JR, Engelhard GH, Pinnegar JK (2010) Ecotypes. In: Rijnsdorp AD, Peck MA, Engelhard GH, Möllmann C, Pinnegar JK (eds) Resolving climate impacts on fish stocks. ICES Coop Res Rep 301, ICES, Copenhagen, p 10-20

Enfield DB, Cid-Serrano L (2010) Secular and multidecadal warmings in the North Atlantic and their relationships with major hurricane activity. Int J Climatol 30:174-184

Enfield DB, Mestas-Nunez AM, Trimble PJ (2001) The Atlantic Multidecadal Oscillation and its relationship to rainfall and river flows in the continental U.S. Geophys Res Lett 28:2077-2080

- Fisher JAD, Frank KT, Petrie B, Leggett WC, Shackell NL (2008) Temporal dynamics within a contemporary latitudinal diversity gradient. Ecol Lett 11:883-897

Froese R, Pauly D (eds) (2009) FishBase. www.fishbase.org

Genner MJ, Sims DW, Southward AJ, Budd GC and others (2010) Body size-dependent responses of a marine fish assemblage to climate change and fishing over a centurylong scale. Glob Change Biol 16:517-527

Greenstreet SPR, Hall SJ (1996) Fishing and the ground-fish assemblage structure in the north-western North Sea: an analysis of long-term and spatial trends. Glob Change Biol 65:577-598

Heessen HJL, Dalskov J, Cook RM (1997) The international bottom trawl survey in the North Sea, the Skagerrak and Kattegat. ICES CM 1997/Y:31. ICES, Copenhagen

Henderson PA (2007) Discrete and continuous change in the fish community of the Bristol Channel in response to climate change. J Mar Biol Assoc UK 87:589-598

Hiddink JG, ter Hofstede R (2008) Climate induced increases in species richness of marine fishes. Glob Change Biol 14:453-460 
Hulme M, Jenkins GL, Lu X, Turnpenny JR and others (2002) Climate change scenarios for the United Kingdom: the UKCIP02 scientific report. Tyndall Centre for Climate Change Research, School of Environmental Sciences, University of East Anglia, Norwich

ICES (International Council for the Exploration of the Sea) (2002) Manual for the International Bottom Trawl Surveys in the western and southern areas. Revision II. Addendum to Report of the International Bottom Trawl Survey Working Group (IBTSWG). ICES CM2002/D:03. ICES, Copenhagen

ICES (2006) Manual for the International Bottom Trawl Surveys. Revision VII. Addendum to Report of the International Bottom Trawl Survey Working Group (IBTSWG). ICES CM 2006/RCM:03. ICES, Copenhagen

ICES (2008a) Report of the International Bottom Trawl Survey Working Group (IBTSWG), 31 March - 4 April 2008, Vigo, Spain. ICES CM 2008 RMC:02. ICES, Copenhagen

ICES (2008b) Report of the Working Group on the Assessment of Northern Shelf Demersal Stock (WGNSDS), 15-21 May 2008, Copenhagen, Denmark. ICES CM 2008/ACOM:08. ICES, Copenhagen

ICES (2009) Report of the Working Group on the Assessment of Demersal Stocks in the North Sea and Skagerrak (WGNSSK), 6-12 May 2009, ICES Headquarters, Copenhagen. ICES CM 2009/ACOM:10. ICES, Copenhagen

Kerr RA (2004) Three degrees of consensus. Science 305: 932-934

Klanderud K, Birks HJB (2003) Recent increases in species richness and shifts in altitudinal distributions of Norwegian mountain plants. Holocene 13:1-6

$>$ La Sorte FA, Lee TM, Wilman H, Jetz W (2009) Disparities between observed and predicted impacts of climate change on winter bird assemblages. Proc Biol Sci 276: 3167-3174

Levin PS, Holmes EE, Piner KR, Harvey CJ (2006) Shifts in a Pacific Ocean fish assemblage: the potential influence of exploitation. Conserv Biol 20:1181-1190

MacKenzie BR, Schiedek D (2007) Daily ocean monitoring since the 1860s shows record warming of northern European seas. Glob Change Biol 13:1335-1347

Macpherson E (2002) Large-scale species-richness gradients in the Atlantic Ocean. Proc Biol Sci 269:1715-1720

Macpherson E, Duarte CM (2006) Patterns in species richness, size, and latitudinal range of East Atlantic fishes. Ecography 17:242-248

Maxwell D, Jennings S (2005) Power of monitoring programmes to detect decline and recovery of rare and vulnerable fish. J Appl Ecol 42:25-37

Menéndez R, Megías AG, Hill JK, Braschler B and others (2006) Species richness changes lag behind climate change. Proc Biol Sci 273:1465-1470

Nye JA, Link JS, Hare JA, Overholtz WJ (2009) Changing spatial distribution of fish stocks in relation to climate and population size on the Northeast United States continental shelf. Mar Ecol Prog Ser 393:111-129

> Parmesan C, Yohe G (2003) A globally coherent fingerprint of climate change impacts across natural systems. Nature 421:37-42

Pauly D, Christensen V, Dalsgaard J, Froese R, Torres F (1998) Fishing down marine food webs. Science 279: 860-863

Perry AL, Low PJ, Ellis JR, Reynolds JD (2005) Climate change and distribution shifts in marine fishes. Science

Editorial responsibility: Konstantinos Stergiou,

Thessaloniki, Greece
308:1912-1915

Perry RI, Cury P, Brander K, Jennings S, Mollmann C, Planque B (2010) Sensitivity of marine systems to climate and fishing: concepts, issues and management responses. J Mar Syst 79:427-435

Petchey OL, McPhearson PT, Casey TM, Morin PJ (1999) Environmental warming alters food-web structure and ecosystem function. Nature 402:69-72

Philippart CJM, Anadón R, Danovaro R, Dippner JW and others (2007) Impacts of climate change on the European marine and coastal environment. Marine Board ESF Position Paper 9, Marine Science Foundation, Strassbourg

Planque B, Fromentin JM, Cury P, Drinkwater KF, Jenning S, Perry RI, Kifani S (2010) How does fishing alter marine populations and ecosystems sensitivity to climate? J Mar Syst 79:403-417

Pyper BJ, Peterman RM (1998) Comparison of methods to account for autocorrelation in correlation analyses of fish data. Can J Fish Aquat Sci 55:2127-2140

> Rice J, Gislason H (1996) Patterns of change in the size spectra of numbers and diversity of the North Sea fish assemblage, as reflected in surveys and models. ICES J Mar Sci 53:1214-1225

Rijnsdorp AD, Peck MA, Engelhard GH, Möllmann C, Pinnegar JK (2009) Resolving the effect of climate change on fish populations. ICES J Mar Sci 66:1570-1583

Root TL, Price JT, Hall KR, Schneider SH, Rosenzweig C, Pounds A (2003) Fingerprints of global warming on wild animals and plants. Nature 421:57-60

> Southward AJ, Langmead O, Hardman-Mountford NJ, Aiken $J$ and others (2005) Long-term oceanographic and ecological research in the western English Channel. Adv Mar Biol 47:1-105

> Stefansdottir L, Solmundsson J, Marteinsdottir G, Kristinsson KN, Jonasson JP (2010) Groundfish species diversity and assemblage structure in Icelandic waters during recent years of warming. Fish Oceanogr 19:42-62

> Stone DA, Allen MR, Stott PA, Pall P, Min S, Nozawa T, Yukimoto $S$ (2009) The detection and attribution of human influence on climate. Annu Rev Environ Resour 34:1-16

ter Hofstede R, Daan N (2008) A proposal for a consistent use of the North sea IBTS data. ICES CM 2008/R:25. ICES, Copenhagen

Thomas CD, Cameron A, Green, RE, Bakkenes M and others (2004) Extinction risk from climate change. Nature 427: $145-148$

Thomas CD, Franco AMA, Hill JK (2006) Range retractions and extinction in the face of climate warming. Trends Ecol Evol 21:415-416

Trenkel VM, Pinnegar JK, Rochet MJ, Rackham BD (2004) Different surveys provide similar pictures of trends in a marine fish community but not of individual fish populations. ICES J Mar Sci 61:351-362

- Walther GR, Post E, Convey P, Menzel A and others (2002) Ecological responses to recent climate change. Nature 416:389-395

Wheeler A (1992) A list of the common and scientific names of fishes of the British Isles. J Fish Biol 41 (Suppl A):1-37

Wheeler AC, Merrett NR, Quigley DTG (2004) Additional records and notes for Wheeler's (1992) List of the common and scientific names of fishes of the British Isles. J Fish Biol 65 (Suppl 2):1-40

> Yang $\mathrm{J}$ (1982) The dominant fish fauna in the North Sea and its determination. J Fish Biol 20:635-643

Submitted: March 17, 2010; Accepted: July 28, 2010

Proofs received from author(s): August 20, 2010 